\title{
Vikings: poder e identidades culturales en la serie de History Channel
}

\section{Vikings: power and cultural identities in the show of History Channel}

\author{
Mayte Donstrup ${ }^{1}$ \\ Recibido: 26-08-2017 - Aceptado: 12-12-2017 \\ DOI: https://doi.org/10.26441/RC17.1-2018-A3
}

\begin{abstract}
RESUMEN: Este artículo estudia, desde un punto de vista antropológico, la formación de identidades en la serie canadiense Vikings (2013- ), creada por Michael Hirst para The History Channel. Con este objetivo, se hace uso de una metodología textual de los fragmentos audiovisuales más relevantes para dicho fin. Los resultados de dicho análisis aportan datos sobre la construcción y la relación entre diferentes identidades, y la discusión de los resultados giran en torno a un núcleo principal: el poder.
\end{abstract}

Palabras clave: Vikings; series; poder; identidad; etnicidad.

ABSTRACT: The aim of this paper is to study from an anthropological perspective the formation of identities in the Canadian tv-series Vikings (2013- ), created by Michael Hirst for The History Channel. With this purpose, we use a textual methodology of the most relevant fragments. The discussion of the results is organized around one main core point that shape the construction of identities in this show: power.

Key Words: Vikings; TV-series; power; identity; ethnicity.

\section{Introducción}

En línea con las novelas históricas, tales como El nombre de la rosa (Umberto Eco, 1980) o Guerra y Paz (Leon Tolstoi, 1869), el cine -y posteriormente las series- se han hecho eco de los grandes relatos en los que basar sus tramas. En el caso televisivo, producciones como la miniserie Band of Brothers (HBO,
2001) o The Tudors (Showtime, 20072010), por poner solo un par de ejemplos, siguen esta línea narrativa. De esta forma, enmarcadas en la tercera edad dorada de la televisión, estas producciones de ambientación histórica plantean las tramas de una forma, en mayor o menor medida, verosímil y con líneas argumentales y escenarios

\footnotetext{
1 Mayte Donstrup es Personal Investigador en Formación en el Departamento de Comunicación Audiovisual y Publicidad. Miembro del grupo de investigación IDECO. Graduada en Publicidad y Relaciones Públicas, con un máster en Comunicación y Cultura. mdonstrup@us.es. https://orcid.org/0000-0001-6236-4967
} 
en concordancia con los personajes históricos que tratan.

En esta temática, el presente artículo analizará Vikings (History Channel, 2013), cuyo argumento gira en torno a Ragnar Lodbrok, figura legendaria de las sagas nórdicas. Una serie que, a pesar de los posibles anacronismos históricos y datos mezclados o inventados, la historiadora especializada en la Era vikinga, Laia San José Beltrán, califica de notable calidad, reflejando la cultura y la sociedad vikinga mucho más acorde a lo que era que otras producciones ficcionales realizadas hasta el momento que han tratado el tema (2015: 45-46). En este sentido, las series constituyen un objeto de estudio de interés para el análisis de los sujetos sociales, y la representación de las relaciones entre diferentes culturas -las cuales se dan en dicha serie- se torna de especial interés para el presente contexto socio-cultural; de esta forma, Cascajosa expresa que "las series de televisión han pasado a ocupar un lugar destacado en el espacio cultural de la sociedad [...] en un proceso de legitimación resultado de una combinación de factores institucionales, socioeconómicos y tecnológicos" (2016: 12). Entonces, sin tener que salir del texto televisivo, estas se consideran interesantes para observar cómo se representan a los sujetos -o grupos- sociales.

\section{Marco contextual}

Tal como afirma la socióloga Buonanno, la televisión actúa como constructora del imaginario colectivo; un hecho, señala la autora, que no solo pertenece a la imaginación, pues esta formación de imágenes es, por sí misma, capaz de modificar nuestra conducta y traspasar al mundo real a través de nuestras acciones (1999: 54). Asimismo, la socióloga otorga a las series, en concreto, una función de entendimiento de la cultura y de la sociedad que expresan. De esta suerte, Buonanno no argumenta que las series de televisión deformen la realidad, sino que la comentan y la interpretan, reabsorbiendo los elementos de la comunidad y dándoles sentido en sus tramas. Al respecto, Buonanno ofrece tres funciones de las series de ficción (1999: 62-66):

- Fabuladora: hablan al espectador y sobre el espectador, pues la televisión cuenta historias sobre ellos mismos. De esta forma, puede aportar hechos y experiencias de la vida cotidiana.

- Familiarización: construyen un sentido común y aportan normalidades, en este sentido, la televisión actúa como un generador de valores comunes y de experiencias compartidas. Por otra parte, puede servir de elemento conservador, sosteniendo unida la cultura y sirviendo de reconocimiento de la misma a través de las imágenes que ofrece.

- Mantenimiento de la comunidad: si bien no es que se oponga a elementos nuevos, la televisión sí que tenderá a aceptarlos paulatinamente. Por otro lado, rechazará todo aquello que considere radical, es decir, lo que se oponga frontalmente con las ideas predominantes de la sociedad. 
En lo que respecta a las series de la temática que aquí preocupa, hay un hecho que marca un antes y un después en los contenidos ficcionales: el 11-S. En este sentido, Fernández Morales (2013) expone cómo la industria modificó el enfoque narrativo que daba a las producciones, tanto fílmicas como televisivas, después de los atentados. Por ejemplo, eliminando todo aquel elemento -como las imágenes de las torres gemelas- de las producciones realizadas anteriormente a los golpes terroristas que pudieran dañar la sensibilidad de los ciudadanos. No obstante, las modificaciones del plano audiovisual no fueron las únicas, pues la argumentación de los contenidos fue orientada hacia una exaltación de patriotismo y hacia una conmemoración hacia todo aquel que había dado la vida por el país. A su vez, este impacto de terror causado en el propio terreno conllevó a que se produjera una nostalgia por el pasado, el cual produjo un auge de las producciones históricas (Fernández Morales, 2013). De ahí que se afirme que "Otro aspecto del discurso histórico en televisión que ha provocado reacciones contrapuestas es su llamado presentismo (presentism), su tendencia a incluir en las narraciones del pasado asuntos y preocupaciones relevantes en el presente de la emisión" (López, 2009: 12); y en este contexto enmarcamos la serie objeto de este estudio, Vikings, que retrata cómo se forman las identidades de dos sociedades, a simple vista, dispares; una cuestión que, a su vez, es objeto de debate en la actualidad, con el tema de la inmigración en la mayoría de dis- cursos políticos -ya sea en Europa con el Brexit (Martínez, 2017); en Australia, que cierra sus puertas a refugiados (Lombraña, 2015); o en Estados Unidos, con el muro de Donald Trump (Ahrens, 2017)- por poner solo unos ejemplos. Por otro lado, se puede resaltar el carácter idóneo de las series históricas para estas representaciones, pues: la recreación televisiva de un tiempo histórico parece ser una estrategia que, entre otras cosas, acredita la veracidad de un relato. La evocación del tiempo pasado en su dimensión más cotidiana, además de hacer las veces de enfoque narrativo original y entretenido, puede incrementar la confianza y la implicación del espectador ante el mensaje (Chicharro Merayo y Larueda Laffond, 2008: 81).

Por lo tanto, diversos estudios han profundizado en el mensaje de las ficciones televisivas históricas y la representación que en ellas se hace de las identidades sociales, un interés que no se aparca en el continente americano: por ejemplo, en el caso español se ha examinado La Señora, resaltando su carácter ideológico, su sentido explicativo respecto a una parte de la historia y, en cierta manera, su tono socializador (Chicharro Merayo, 2009a). En el mismo contexto español, el caso de Amar en Tiempos Revueltos recrea "una conflictiva etapa de la historia española próxima, ofreciendo explicaciones sobre el pasado y el presente que, si bien ficticias, adquieren una carga realista a través de la credibilidad propia del lenguaje audiovisual" (Chicarro Merayo, 2009b: 96). Ya en el panorama estadounidense, 
por ilustrar con solo un par de casos, se encuentran análisis de la serie Outlander (Donelan, 2017), una mezcla de fantasía e historia, o de la misma serie de Vikings, en la cual la investigadora Katarzyna Puchalska afirma:

It seems that the creators of the television series tried to use all possible sources on the Viking Age and make Vikings as interesting as possible for the viewers, without necessarily paying heed to the credibility of the presented phenomena. After all, the show is entertainment, not a documentary programme, and the audience should be aware of that fact. Still the preparation of the History Channel and its willingness to convey the climate of the early medieval times deserves praise. Even though in their work history intermingles with legend, it might inspire future enthusiasts and researchers and widen our knowledge on the Viking world. I have no doubts that the Vikings series will be remembered as one of the milestones for the popular cultural motif of the Norsemen and that popular culture is our modern mythology (2015: 102).

\section{Objetivo}

El propósito de este artículo es comprender la formación de identidades de las dos sociedades narradas en la serie, la vikinga y la inglesa. Una especificación que, sin embargo, contará en mayor detalle la sociedad nórdica, siendo el poblado en el que haga mayor hincapié la producción desde el punto de vista narrativo. En este punto, señalar que la exposición realizada corresponde a los datos reflejados en la serie, siendo en ciertos puntos modificados respecto a la realidad sucedida para añadir atractivo a la trama (San José Beltrán, 2014: 12-15). Por consiguiente, el análisis de este estudio se basará en la recreación audiovisual de Vikings, estudiando a los personajes y los hechos mostrados en el texto televisivo.

\section{Metodología}

Por lo que respecta a la metodología empleada, desde una perspectiva cualitativa se realizará un análisis textual de Vikings como estudio de caso; en concreto, se hará un especial énfasis de la relación establecida entre los personajes de Ragnar, Athelstan y Ecbert. La atención en estas tres figuras se realiza en base en su representatividad respecto a la conformación de identidades, tanto en su activación como en su desactivación. En cuanto al intervalo temporal, la muestra se basa en las tres primeras temporadas -de nueve capítulos la primera y de diez las siguientes dossiendo un total de veintinueve unidades de análisis. Con el fin de ejemplificar los conceptos, se han realizado referencias a escenas y capítulos de la serie a fin de ilustrar los planteamientos discutidos.

Para el estudio de los personajes se ha tenido en cuenta bibliografía especializada (Casseti y Di Chio, 2010; Brisset, 2011). Así, se tomarán los presupuestos de la descomposición del material audiovisual para una mejor descripción e interpretación; una fragmentación en la que serán analizadas diferentes 
secuencias, es decir, unidades de contenido dentro del todo que tienen su propia historia dentro de la temática general del producto audiovisual (2010: 41). Para ello, se tendrán en cuenta los conceptos relato audiovisual y texto televisivo; el primero, hace referencia a "la producción televisiva desde una perspectiva narratológica" (Tous, 2010: 20), el segundo, a los significados de estas narraciones (Buonanno, 1999). Por otra parte, para el análisis de los personajes se tendrá en consideración su rango como persona, es decir, este será considerado con una personalidad única y poseedor de un rango de matices propios que constituirán su identidad (2010: 178). En consecuencia, se valorará especialmente "Las reacciones de los personajes, su manera de hablar o de moverse, [pues estos] son recursos esenciales para la exteriorización de su psicología y su caracterización” (Galán Fajardo, 2007: 3). En definitiva, combinando elementos de la narrativa audiovisual -naturaleza antagónica o protagónica; principal o secundario; rol actancial (papel que desempeña)- y estudios antropológicos Eriksen. Comaroff y demás autores desarrollados en el marco de resultados- se ha procedido a caracterizar a los principales personajes más interesantes para el objeto de estudio: la formación de identidades.

\subsection{Muestra de análisis}

Respecto a los fragmentos seleccionados para el análisis, con la intención de escoger aquellos momentos centrales, se ha seguido a Chatman (2013), que expone que los sucesos narrativos -es decir, acontecimientos o acciones- en un nivel mayor de jerarquía de la historia son aquellos que no pueden ser eliminados, pues si se eliminaran, la historia carecería de sentido. Por ende, estos se pueden considerar los núcleos de la misma, es decir, "momentos narrativos que dan origen a puntos críticos en la dirección que toman los sucesos" (2013: 71). De este modo, se han seleccionado los fragmentos considerados como núcleos de la historia de la relación entre los principales personajes a analizar.

En total, el estudio ha analizado un total de 28 secuencias de las tres primeras temporadas de Vikings (29 episodios) como universo total de estudio; se ofrece a continuación algunos datos de la trama general de la serie y de los personajes para esclarecer la importancia de las secuencias seleccionadas de los análisis, así para que sirva a modo de guía para la ilustración de los resultados obtenidos del siguiente apartado:

Creada por Michael Hirst para History Channel, Vikings se estrenó en marzo de 2013 y en la actualidad permanece en la parrilla televisiva a la espera del estreno de una sexta temporada. Con una estética cuidada, cercana a la evocación de elementos mitológicos, y un reparto coral de nueve personajes, la serie narra desde las primeras incursiones vikingas a los poblados de la costa inglesa, expediciones que darán lugar a una convivencia entre diferentes culturas, con sus afinidades y sus conflictos. Los episodios de la primera temporada relatan las distintas reacciones de estos personajes ante el descubrimiento de las nuevas tierras y de las 
nuevas culturas; la segunda, el proceso de adaptación ante las nuevas experiencias; en la tercera, por su parte, se puede distinguir por los procesos de conflicto en los que entran los personajes, ante la decisión de aceptar o rechazar las diferentes identidades del escenario.

Sobre los personajes principales, se han escogido para el análisis tres: Ragnar Lodbrock, Athesltan y Ecbert. Esto se debe a que son ellos tres los que juegan un papel central en los acontecimientos y desenlaces de las temporadas. El primero de ellos, Ragnar, es el principal responsable de la llegada de los vikingos a costas inglesas, además, será la persona que lidere las incursiones en todas los demás episodios, siendo uno de los vikingos más respetados y admirados en su poblado; Athelstan es el monje cristiano que acaba prisionero y que terminará convirtiéndose en el mejor confidente de Ragnar, estableciendo una sólida relación de amistad con él, una integración en su nuevo estilo de vida que, por otra parte, le llevará a dilemas morales; por último, Ecbert, un ferviente cristiano, es un monarca inglés que se convertirá en el mayor aliado -y enemigo- del líder vikingo.

\section{Resultados}

A modo de resumen, la trama argumental de la serie Vikings gira en torno al personaje Ragnar Lodbrok, perteneciente a la sociedad vikinga, un granjero y valorado guerrero que se interesará por tierras más lejanas. Identificado con el dios Thor, realizará un camino de continua superación a través de los capítulos, llegando a ser por méritos propios duque y posteriormente rey. Puestos que ha ido ganando progresivamente gracias a sus exitosas incursiones, descubriendo nuevas tierras para su poblado, repletas de riquezas y posibilidades. Y en aquellos terrenos, situados en Inglaterra, tiene lugar su encuentro con Athelstan, un monje del convento de Lindisfarne, y el cual habla su idioma, una oportunidad de saber más sobre aquellas tierras desconocidas que Ragnar no dejará escapar, llevándose a Athelstan con él en condición de esclavo; una posición que será sustituida en el transcurso del tiempo a hombre libre. A partir de ese punto, con la información obtenida a través del monje, los retornos a Inglaterra se irán tornando más productivos hasta su llegada, por accidente, a otro territorio: Wessex, siendo en aquel lugar el encuentro con el monarca Ecbert, que considerará la llegada de los vikingos como una ocasión a la que intentar sacar provecho.

Asimismo, cabe señalar el preámbulo de cada sociedad expuesta en la serie; Ragnar Lodbrok es presentado en las primeras escenas como un habilidoso guerrero, padre de familia y ávido de curiosidad. Lagertha, su mujer, es representada enseñando a su hija, Gilda, las tareas del hogar, tales como pescar y tejer, mientras el primogénito, Björn, es enseñado a pelear por el padre e iniciado como hombre en un ritual en la aldea (1x01, "Rites of Passage"). El primer capítulo deja tras de sí, entonces, un primer acercamiento a la composición de 
la estructura familiar y las tareas asignadas a cada miembro familiar de la sociedad vikinga. De esta manera, siguiendo a Geertz (1992: 54), entender que más que un hábito o tradición, la tarea realizar las labores del hogar será para Gilda una instrucción para manejarse en la sociedad una vez casada y con familia. Igualmente, Ragnar traslada a su hijo los métodos de lucha eficaces para ser un respetado vikingo en el futuro. En definitiva, actos y pensamientos sociales que contienen significaciones, facilitando la vida comunitaria con normas no escritas (1992: 57). Por otro lado, en las primeras secuencias interviene otro escenario en la costa inglesa, que muestra a Athelstan ataviado con vestimenta de monje y rezando, al señor Jesucristo, debajo de una cruz cristiana. Un conjunto de artes y costumbres igualmente, y, en este sentido, un caso paradigmático se presenta en este primer acercamiento a la sociedad vikinga: Ragnar ha descubierto un rudimentario pero novedoso sistema de navegación, el cual a través de la sombra proyectada de una piedra en una tabla les permitirá guiarse para realizar incursiones en el oeste. Un elemento cultural que puede cambiar la tradición del poblado de realizar expediciones en el este, un hecho que no será del agrado del detentor del poder en ese momento: el conde Haraldson. De esta forma, la brújula será el elemento que permitirá ir a través de nuevas vías marítimas a Inglaterra: un lugar donde tendrá el encuentro con otras sociedades y que pondrán en marcha las identidades políticas.
En Wrath of the Northmen (1x02) hace presencia la cosmovisión vikinga: la mitología nórdica, que relata los sucesos del mundo y posee las ideas sobre el mundo de la sociedad, dando significado a los hechos y aportando conocimiento (Geertz, 1992: 118-120). Así, Lagertha traspasa a sus hijos su visión del mundo:

The great sea is held in place by Jormungand, the serpent, whose giant body encircles it, and whose keeps his tail and his mouth, to complete the circle and stop the waves breaking loose. But one day, the God Thor, son of earth, was fishing in the sea for the serpent, using a bull's head for bait. Jormungand reared up and the waves pummeled the shore and he twisted and writhed in a fury. They were well matched, serpent and God, in that furious fight. The seas boiled around them, but then the hook became dislodged, and the serpent slithered free and sank again, so quickly, beneath the waves. And soon, the sea was calm once more, as if nothing had disturbed it.

Un relato que ofrece las causas y porqués de unos hechos, a fin de heredarles a sus vástagos los motivos por los cuales se rige la tierra, creando los imaginarios sociales que va a regir sus acciones en el transcurso de sus vidas. En este sentido, resulta de interés observar cómo, a través del proceso comunicativo, se insertan pensamientos que originarán distintas connotaciones ante los hechos. Así, en el mismo episodio tiene lugar una tormenta que obtiene dos interpretaciones distintas según provengan desde el 
punto de vista vikingo o del cristiano: el primero concibe la tempestad como una señal, el segundo, la interpreta como un hecho natural. Revelando de esta manera el influjo inconsciente asimilado desde las instituciones sociales, que resulta en convertir en incuestionable los significados dados a los eventos acontecidos: la tormenta es para los primeros un signo evidente de Thor y para los segundos un suceso atmosférico, sin más discusión posible por parte de ambos. Asimismo, una vez en tierra y ya saqueado el monasterio, en Dispossessed (1x03) Athelstan aparece siendo llevado como esclavo a Kattegat, y en ese tramo de viaje, interpreta su apresamiento como un castigo por sus pecados. Una idea que le parece ridícula a Ragnar, pues entiende que está allí porque le ha perdonado la vida. Por consiguiente, evidenciando la dificultad que tienen dos culturas para entender el punto de vista de la otra, este capítulo tiene en esencia las características del choque cultural, sobre todo experimentado por Athelstan, que una vez en tierras vikingas, observa incrédulo las costumbres del pueblo captor.

En Raid (1x05) acontece uno de los procesos más importantes para Athelstan para su proceso de integración social, interesándose por los dioses que componen la mitología vikinga y la constitución del Gran Salón. Un proceso de socialización secundaria en este caso, pues su socialización primaria, es decir, la asimilación inconsciente de la cultura (Monzó, 2003), fue en la sociedad inglesa. Un suceso que se torna en inevitable para él, pues al entrar en contacto con otra cultura y al convivir con sus miembros, queda irremediablemente afectado y repercute en su manera de actuar y de pensar. En este sentido, entre todos los vikingos reunidos en la habitación le explican sus dioses y cómo fue la creación de la tierra según sus creencias. En contra, el proceso de socialización es una evolución por fases y debe transcurrir un plazo de tiempo, y puede resultar no ser tan sencillo completarla, tal como se aprecia en el capítulo Sacrifice (1x08). En este episodio Athelstan asiste a los ritos en Uppsala, con atuendos y actitud vikinga, conociendo según transcurre el día los sacrificios que se realizan allí para atender a los dioses; nueve animales de cada especie deben ser ofrecidos para contentarlos, entre los cuales se encuentran los humanos, con el objeto de conseguir nueve años de buena fortuna en el poblado. Un rito que será débilmente asimilado por el monje y que llevará a que, en los últimos momentos del episodio, reconozca ante los sacerdotes vikingos que sigue abrazando la fe cristiana, un hecho que, sin embargo, resultará en salvarle la vida inconscientemente, pues iba a ser ofrecido como sacrificio por parte de la familia de Ragnar.

Un proceso de socialización que parecerá culminar en la segunda temporada, pues, tras el lapso temporal de cuatro años que tiene lugar en Invasion (2x02), Athelstan aparece entrenándose para luchar junto a Ragnar. Decidido a ir con ellos para batallar y no quedarse atrás es en este viaje de vuelta a Inglaterra, siendo en aquella primera incursión cuando mate por primera 
vez, sin ninguna duda y salvando a Ragnar por ello. Una acción que le valdrá para que le sea otorgada la pulsera, significante de pertenecer por completo al poblado vikingo. Un elemento con una gran carga de simbólica, estableciendo un nexo de unión con los vikingos, especialmente con Ragnar, con el cual ha creado una relación de amistad. En esta línea, resulta sustanciosa la relación entre ambos en términos culturales, ilustrando cómo dos personas con ideas preconcebidas tan diferentes han logrado llegar a un entendimiento y respeto. Si bien el antiguo monje ha adoptado sus costumbres, el vikingo se interesa igualmente por las creencias y costumbres de su amigo. Tal como se aprecia en el siguiendo episodio ("Treachery", 3x02): pues en el saqueo de una iglesia de Wessex, Ragnar se interesa por el significado de "santo". En este sentido, se refleja la incertidumbre que una persona puede tener respecto a otra aun compartiendo el mismo idioma (Wittgenstein en Geertz, 1992: 2627), pues cuando le explica Athelstan con otras palabras el significado de "santo", aun no logra entender la utilidad de una persona muerta. Incomprensión que viene dada por intentar comprender lo que no se puede entender en función del propio repertorio cultural (Geertz, 1992). En esta línea, Ragnar no entendía la adoración a una persona muerta cuando sus dioses estaban vivos y podían bajar a la tierra para realizar tareas físicamente. De esta manera, tal como comenta Eriksen, a una cultura hay que comprenderla en sus propios términos (2010: 6).
¿Y en qué puede derivar aquella incomprensión? El lenguaje, entre otros elementos, configura realidades y comprensiones del mundo en el que se habita. Por consiguiente, diferentes lenguajes constituirán distintas configuraciones de la realidad de cada grupo -en este caso el escandinavo y el inglés- así como posibilitan que sean utilizadas esas diferencias comunicativas políticamente en la formación de identidades, y con una alta probabilidad de desarrollo. En esta dinámica, Ecbert, el monarca inglés, aparece en la trama narrativa y surgen dos grupos claramente diferenciados en un "nosotros vs ellos"; comunidades altamente diferenciadas entre ellas, visionadas la una a la otra con características homogéneas y demonizadas entre todos los miembros del grupo opositor: por parte de la sociedad inglesa, los paganos son salvajes que no aprecian la vida, por parte de la sociedad vikinga, los cristianos son "estúpidos" que adoran a personas muertas. El hecho que sus propios comportamientos y actitudes estén tan naturalizados para cada uno de ellos, comporta que modos de vida diferentes les sean tan extraños, anormales, y ello es una herramienta para los detentores del poder en aras de conservar o mantener su porción de autoridad. A su vez, entra en el juego el denominado punto ciego, "relacionado con el pensamiento dominante [...] que implica el establecimiento de un nosotros distorsionado; nosotros siempre somos los buenos frente a ellos los malos" (Huici Módenes, 2017: 35). Elementos que, una vez sumados, 
implican: "El primer mártir del pensamiento colectivo [sea] la capacidad crítica de sus integrantes [...]. La lealtad al grupo requiere que sus miembros no manifiesten cuestiones embarazosas, ataquen los argumentos más débiles o traten de rebatir los cuestionamientos" (Goleman, 1997: 257).

En este caso, para la formación de grupos diferenciados se valdrán de su historia pasada, así como el uso de un mismo idioma, para reforzar su unión entre ellos, e igualmente, la formación de estereotipos del contrario para animar a su animadversión. Y el hecho de formación de estas identidades no guarda relación con la causa geográfica se ha comprobado en distintos episodios: entre los poblados vikingos las identidades han estado diferenciadas entre ellos, cada uno pertenecía a su terreno y las disputas internas por el poder no cesaron. Sin embargo, el hecho de encontrar un "enemigo" exterior común, ha conseguido la unión entre las distintas formaciones étnicas con el objetivo de un mayor beneficio conjunto en Inglaterra. En este sentido, en el territorio inglés se ha observado la misma técnica, las disputas internas han dejado lugar a alianzas y agrupaciones que den mayor fuerza para luchar contra el contrario.

En relación al sentido de pertenencia, Athlestan a lo largo de estos capítulos ha pasado de sentirse cristiano a sentirse parte de la sociedad vikinga: tiene sentimientos de solidaridad hacia ellos, se encuentra cómodo en Kattegat, siente a Thor en las tormentas y participa en sus actos sociales con una natural integración. Un hecho que le condena ante los ojos de su antigua fe, pues una vez que lo apresan en una de las incursiones en su tierra de origen, es crucificado en nombre de Jesucristo ("Eye for an Eye”, 4x02). Una crucifixión de la que es salvado por el rey Ecbert, que ordena bajarlo de la cruz, pues al igual que Ragnar apreció en su primer encuentro, advierte en él una posibilidad de conocer más sobre la sociedad vikinga, información desconocida y de interés para proteger sus bienes. Es a partir de este momento cuando el monarca mantiene a su lado a aquel antiguo monje y, en Anwers in Blood (2x05), acontece una de las primeras escenas en su reinserción en la sociedad inglesa: en el transcurso de un juicio donde se encuentra en valoración el castigo a una mujer en sospecha de adulterio. Allí, Ecbert siente curiosidad por el dictamen que tendrían los vikingos en este caso, y Athelstan le comenta que, al ser una mujer libre, la creerían a ella, que niega el crimen moral del que es acusada. Un hecho que asombra al rey y le hace preguntar si acaso por ello los vikingos son mejores que los cristianos. Ante esta interrogativa, Athelstan responde tal como podría responder un etnógrafo: no es cuestión de valorar la superioridad de una u otra, son distintas maneras de apreciar los hechos, diferentes concepciones de entender la vida.; pues el objeto de la antropología no es juzgar una cultura (Eriksen, 2010).

Respecto a la dicotomía entre identidades, ¿en qué lugar se encuentra el joven fraile? En la misa que tiene lugar 
posteriormente, escupe la hostia sagrada de la ceremonia. Un símbolo que le vincula con la creencia cristiana que rechaza según parece, sin embargo, acude a una plegaria después de los servicios religiosos a fin de que se muestre ante él de nuevo Dios. Una petición que le es negada y muestra en el monje gran angustia, teniendo sucesivamente alucinaciones intercaladas de las creencias nórdicas y las cristianas alternativamente. En esta escena concretamente las visiones marcan un devenir del personaje, que resultará en una eterna batalla por la identificación asimilada en ambos grupos, un sentir de pertenencia vikingo e inglés que, si puede parecer sensato a primera vista por el hecho de haber convivido un largo espacio en ambos, a sentir de cada uno de los grupos será concebido como anti-natural. Es por ello que la reintegración en la sociedad inglesa no se deduce fácil para Athelstan, pues aun siendo cristiano, no es considerado como uno de ellos por la mayoría. Si bien es cierto que estaba totalmente integrado en la sociedad pagana, esta adhesión no es mostrada ante el público inglés, disimulando perfectamente ante ellos sus creencias nórdicas y mostrando su fe cristiana que, por otra parte, no resulta falso que haya dejado de sentir. Entonces, es en este preciso punto en el cual se marca que no son diferencias reales las que establecen las distancias entre los grupos, sino las creadas y activadas en determinados momentos (Comaroff, 1994). Si bien el monje fue apresado y se adaptó a costumbres paganas, en el retorno reanudó sus labores de escriba y, lo más importante para los ingleses, seguía siendo cristiano. No obstante, no es suficiente para el pueblo o los nobles, que le adjudican las características de los hombres bárbaros y sienten desconfianza hacia él. Un pensamiento que, sin embargo, no es compartido por el monarca, que le convierte en su hombre de confianza y comparte con él productivas conversaciones, creando a lo largo de los episodios incluso una relación de amistad.

¿Y por qué esta diferencia es visible para unos, pero para el detentor de poder no? En este juego de identidades, el poder es el que marca las oposiciones (Castells en Comaroff, 2012), las cuales son simplificadas para una mayor asimilación por parte del pueblo. Athlestan, a ojos del pueblo, es un bárbaro salvaje, y difícilmente dejará de serlo mientras las diferencias respecto a los otros sigan activadas. Mientras, en privado esas desavenencias desaparecerán, y Ecbert hasta le muestra una admiración por las costumbres paganas de los anteriores habitantes de las islas británicas ("The Choice", 2x09). Llegando incluso a adoptar en el siguiente ataque de los vikingos técnicas de los romanos, con las cuales conseguirá la primera victoria sobre los escandinavos, lo cual le permitirá tomar posición para negociar por primera vez, siendo Athelstan el que vaya al asentamiento al encuentro de su antiguo clan.

Realizando un paréntesis, ha surgido la denominación de bárbaro en el transcurso de la serie, asignado ese término a la población vikinga por parte de los ingleses. Tomando la postura absoluta 
asignada por el autor Todorov: bárbaro es aquel que es cruel y feroz, que niega la humanidad del contrario y por ello, le trata sin el más mínimo respeto por su integridad, física o moral. Por el contrario, la civilidad es aquel don que reconoce las diferencias del contrario y acepta su humanidad, tratándole como tal, con respeto y comprensión (2008: 33-39). Una vez definidos los conceptos, ¿quién es el verdadero bárbaro de la serie Vikings?, o mejor cuestionado: ¿Hay civilidad en alguno de ellos? Se pueden mostrar cuantiosos ejemplos de ambos que discutan su civilidad, por poner un par de ambos: en el capítulo The Usurper (3x05) Ragnar se entera, gracias a un superviviente, que Ecbert ha roto su pacto y ha masacrado a su gente en las tierras cedidas en Inglaterra. A fin de que no estropee sus nuevos planes de ir a saquear París, lo estrangula en la misma sala. Por otra parte, en Wrath of the Northmen (1x02) se visiona una violación de parte del hermano de Ragnar a una esclava que, al pertenecer a una condición social de baja escala, es un hecho considerado sin importancia por ellos, pues puede hacer con ella lo que quiera. En la facción inglesa, en Treachery (2x03) Athelstan es crucificado por apóstata y en Burial of the Dead $(1 \times 06)$ el rey Aelle, de Northumbria, arroja a su antiguo general a un pozo de serpientes por no haber repelido a los vikingos en sus ataques. Sin pretensión de calificar estos actos como hechos reprobables o no y asumiendo la descripción realizada por Todorov de bárbaro o cívico, se puede afirmar que ambos poseen cualidades de uno y del otro. Esto viene dado por la consecución de los intereses de ambos, que explica que incluso se llegue a dañar a gente propia a su grupo por ello. Por otra parte, en la formación de identidades se ve que se justifica la violencia hacia la opuesta fracción, puesto que para ellos es una acción necesaria imponer un temido respeto a fin de que se ceda en su favor. De este modo se distingue que el reconocimiento o no de la humanidad depende de las circunstancias dadas, existen actos asimilados como censurables por ambos, pero que, según los intereses en juego, pueden ser ejecutados, ya sea incluso con los miembros de su misma comunidad. Y en ello juega otro importante factor, reconocer la diferencia y aceptarla, ¿̇aceptan a las personas distintas estas sociedades? En efecto, ambas culturas se muestran herméticas y sienten recelos ante las características extrañas.

Retomando a Athelstan, en su reunión con el pueblo nórdico decidió volver con ellos, y en The Lord's Prayer $(2 \times 10)$ reaparece en el poblado, terminando la temporada enseñando a Ragnar a rezar, apreciando que mismamente el rey vikingo ha sido afectado a lo largo de estas temporadas por la incorporación del antiguo monje y convertido en su amigo. Así, él se ha hecho consciente de las particularidades culturales vikingas al entrar en contacto con Athelstan, y al igual que al principio quiso información para sacar ventaja estratégica sobre el enemigo, en la actualidad busca un acercamiento y compresión hacia él. En este sentido, tomando las palabras de Todorov, las 
culturas son siempre mixtas, absorbiendo continuamente características de las otras culturas con las que entran en contacto (2008: 88). De este modo, los sujetos forman su identidad en base a estos contactos, realizando acciones y tomando decisiones influenciados por estos. En contra, a pesar que las culturas sean vistas desde fuera como variables y siempre en proceso de transformación, los miembros del grupo las consideran diferenciadas y estables (2008: 88). Tal se discierne en los encuentros sucesivos entre ambas sociedades: en el inicio de la tercera temporada Athelstan tiene nuevamente un reencuentro con su antigua sociedad, en un clima totalmente distinto al de la segunda, pues los saqueos se han dejado de lado para dar lugar a un ambiente de negociaciones y acuerdos en provecho mutuo. En este aspecto, tal como se percibe en los salones de negociación y el flirteo entre Ecbert y Lagertha en los sucesivos capítulos de esta temporada-, la identidad cultural entre ambos es desactivada y las relaciones surgen en términos de relativa igualdad. Tal como le comenta el monarca inglés a Athelstan ("Warrior's fate", 3x02): él le ha enseñado que culturas diferentes pueden entenderse. ¿Significa aquello que se consideran como una misma unidad? En el mismo capítulo se visiona al primogénito de Ecbert perdonando la vida a un soldado enunciando las palabras "no todos somos como los del norte". Un comentario que deja en evidencia la consideración de tener su grupo una superioridad moral y humana respecto a los vikingos, un juicio existente de ellos, clasificando al grupo vikingo como salvajes inmorales carentes de sentimientos. Por lo tanto, si la identidad personal la pueden desactivar y transformar más fácilmente, no así la colectiva, que para los miembros internos será una característica de gran diferenciación e inamovible. Así, podrán tener un contacto más cercano personalmente entre los miembros de ambos grupos, pero no así con el grupo en sí, que queda totalmente separado, pues la sociedad inglesa y vikinga no pueden parecerse en aras de conservar su identidad grupal.

Reanudando el sujeto principal de este estudio, Athelstan, este se muestra en un modo de vida totalmente afín al pueblo nórdico con sus costumbres, no tanto así con su creencia, pues tras una nueva crisis de fe acabará abrazando la religión cristiana, retomando los rezos y la indumentaria característica. De esta manera, mientras está realizando una oración en su cuarto, Floki, fiel amigo de Ragnar, acude a matarlo ("Reborn", $3 x 06)$. Una enemistad que llevaba germinando desde el principio de la serie y que culminará con el asesinato de Athelstan. Una violenta muerte que, siendo supuestamente una ofrenda a sus dioses, es más bien un encubrimiento y un asesinato por celos de Floki, que no toleraba la relación de amistad del fraile con Ragnar. En este sentido, los asesinatos en nombre de dios (o dioses) adquieren una mayor justificación, por ser considerado lo que se tenía que hacer en nombre de la fe, sin embargo, es un acto que Ragnar no perdonará (“Dead", 3x10). 
En síntesis, realizando un breve recorrido por la trayectoria de Athelstan, se puede decir que realizó su incorporación al poblado vikingo tal como lo hizo Malinowski (2005) en su primera incursión en el poblado de mar del sur de Kula. Con la diferencia entre ambos que el primero fue en calidad de esclavo en sus inicios, siendo no obstante posteriormente como un etnógrafo que se adapta a un nuevo modo de vida para entender las costumbres del pueblo estudiado. Tal es así que se produjo una entrada en la aldea repleta de curiosidad por el pueblo adoptante, como demuestran los niños de la familia al tocarle y preguntarle y unas primeras muestras de cordialidad que eran cortadas por la falta de comprensión cultural entre ambos. Hasta llegar, sin presión y de manera natural, un curso de la vida en armonía con el poblado, logrando una identificación con ellos y su estilo de vida; y al igual que él se hizo a la vida vikinga, ellos lo integraron en su rutina, ya sea con más o menos resistencia. Una integración total, ya sea en religiosa; con la creencia en sus dioses, técnica; haciendo uso de sus armas; y organizativa social, con el paso de esclavo a hombre libre. De esta forma, observando su manera de actuar en casos concretos y deduciendo su maquinaria social, actuando como una especie de informante en doble sentido, para los ingleses y para los vikingos. En el primer caso tal es el ejemplo de comentarles como actuarían ellos ante la palabra de una mujer libre ("Anwers in Blood", 2x05), en el segundo, decirles las horas del domingo durante misa que la ciu- dad queda vacía e indefensa ("Wrath of the Northmen", 1x02). Así, realizando un trabajo de campo que se podría decir que es desde una perspectiva emic, un punto de vista del nativo. Un símil que se puede usar sin olvidar que Athelstan, usando las técnicas del etnógrafo, llegó allí para en principio quedarse.

\section{Conclusiones}

Esta investigación corrobora la formación de identidades en la serie Vikings, no obstante, desde el punto de vista académico, el verdadero punto de interés consiste en el descubrimiento de que las identidades formadas son activadas o desactivadas según el interés del sujeto del poder en el momento. Este último punto ha sido el foco de este artículo, que ha intentado arrojar luz sobre el modo en que esta producción ficcional canadiense ha construido el discurso sobre la identidad. A saber, estas formaciones identitarias han sido puestas de manifiesto hasta entre integrantes de la misma zona geográfica, evidenciando que la formación un grupo depende de los intereses en juego de un grupo o sujeto que se encuentre en posesión del poder y no tanto de la pertenencia genética o geográfica, por ejemplo. Además, cabe resaltar la representación que se ha hecho sobre la posibilidad de entendimiento mutuo entre diferentes identidades culturales, con el caso más destacado de la relación de amistad entre Athelstan y Ragnar.

En consecuencia, centrando el argumento en las sociedades inglesa y vikinga, y no tanto en las disputas internas 
de cada grupo, si algo tienen en común culturas tan dispares es la primacía que dan al asunto de formación de diferencias respecto a la contraria con el objeto de verse a sí mismas unificadas y sólidas en momentos de conflicto. En contra, en periodos de paz, Athelstan ha podido integrarse en ambas a través de un proceso de culturación, absorbiendo elementos de cada una e integrándolos en su propia identidad, mostrando al espectador el enriquecimiento personal obtenido con la asimilación de las dos culturas. Entonces, la serie ha desvelado la posibilidad de adaptación cultural, la cual en época de negocios provechosos entre ambos ha sido vista sin ningún problema. Sin embargo, en tiempos de disputa, las identidades se han reforzado y el hecho de ver al otro como externo hizo que miembros del grupo vieran en determinados momentos al monje con las características estereotípicas del grupo opuesto, con ello, provocando desconfianza en ciertas situaciones. De esta forma, en esta dicotomía es en la cual se ha visto envuelto el fraile; no obstante, ha sido usada sabiamente por él para actuar como mediador entre ambas culturas, pues el hecho de comprender a las dos desde dentro le ha permitido desarrollar una empatía por igual tanto la sociedad nórdica como en la inglesa. Así, la pertenencia total de Athelstan en la sociedad adoptante vikinga se ha visto realizada con éxito, siendo en el último capítulo de la tercera temporada cuando Ragnar decida pedir justicia por su muerte: un derecho que se da a los componentes del grupo.

De esta forma, el análisis desarrollado concluye con la afirmación del interés que estos textos poseen para la interpretación de la representación de los grupos sociales. En este sentido, se antojaría interesante la apertura de más líneas de investigación de casos de estudios aislados, como los desarrollados aquí en el presente artículo con Vikings, con el objetivo de identificar qué discursos y construcciones sobre las diferentes identidades sociales se transmiten en las obras televisivas de un determinado contexto. En esta línea, tal como se ha expuesto en el marco contextual, las series de ficción configuran imaginarios que pueden traspasar a la realidad social y, bajo esta premisa, la representación que se haga sobre las relaciones sociales en las ficciones importa.

\section{Bibliografía}

Ahrens, J. M. (2017). Trump pide fondos para el muro con México a cambio de un acuerdo sobre los 'dreamers. El País. Washington. Recuperado de: https:/elpais.com/internacional/2017/10/09/actualidad/1507535244_918287.html

Brisset, D. (2011). Análisis fílmico y audiovisual. Barcelona: VOC.

Buonanno, M. (1999). El drama televisivo. Identidad y contenidos sociales. Barcelona: Gedisa.

Cascajosa Virino, C. (2016). La cultura de las series. Barcelona: Laertes.

Casetti, F. y Di Chio, F. (2010). Cómo analizar un film. Madrid: Paidós. 
Chatman, S. (2013). Historia y discurso. La estructura narrativa en la novela y el cine. Barcelona: RBA.

Chicharro Merayo, M. M. (2009a). Recreando la sociedad del pasado: modernización y conflicto social en La Señora. Análisi, p. 51-70.

Chicharro Merayo, M. M. (2009b). Información, ficción, telerrealidad y telenovela: algunas lecturas televisivas sobre la sociedad española y su historia. Comunicación y Sociedad, (11), p. 73-98.

Chicharro Merayo, M.M. y Rueda Laffond, J.C. (2008). Televisión y ficción histórica: Amar en tiempos revueltos. Comunicación y Sociedad, XXI (2), p. 57-84.

Comaroff, J. (1994). Etnicidad, violencia y política de identidad. Temas teóricos, escenas sudafricanas. A Coruña: Universidad de A Coruña, Servicio de Publicación, p. 205-225. Recuperado de: https://dialnet.unirioja.es/servlet/articulo?codigo $=1997558$

Comaroff, J. (2012). On ethnicity. In the Ongoing Present. En: On Ethnicity. p. 38-46.

Donelan, C. (2017). Sing Me a Song of a Lass That is Gone: Myth and Meaning in the Starz Original Series Outlander. Quaterly Review on Film and Video. 35(1) p. 31-53.

Eriksen. T. (2010). Anthropology: Comparison and context. En: Small places, large issues. An introduction to Social and Cultural Anthropology. London: Pluto Pass. p. 1-9.

Fernández Morales, M. (2013). Introducción: ¿diez años no es nada? Consecuencias culturales del 11-S. En M. Fernández Morales (Ed.), La década del miedo. Dramaturgias audiovisuales post-11 de septiembre. Switzerland: Peter Lang. p. 13-50.

Galván Fajardo, E. (2007). Fundamentos básicos en la construcción del personaje para medios audiovisuales. Repositorio institucional de la Universidad Carlos III de Madrid. Recuperado de: http://hdl.handle.net/10016/5554

Geertz, C. (1992). La interpretación de las culturas. Barcelona: Gedisa.

Goleman, D. (1997). El punto ciego (psicología del autoengaño). Barcelona: Plaza y Janes.

Huici Módenes, A. (2017). Teoría e Historia de la Propaganda. Madrid: Síntesis.

Katarzyna Puchalska, J. (2015). Vikings Television Series: When History and Myth Intermingle. The Polish Journal of the Arts and Culture (15). p. 89-105.

Lombraña, L.M. (2015). La solución de Australia, la pesadilla de los refugiados. El País. Sidney. Recuperado de: https://elpais.com/elpais/2015/08/10/planeta_futuro/1439219902_423535.html

López, F. (2009). Introducción: el pasado en la pequeña pantalla. En F. López, E. Cueto Asín, D. George Jr. (Eds.). Historias de la pequeña pantalla. Representaciones Históricas en la televisión de la España Democrática. Madrid: Iberoamericana. p. 9-25.

Malinowski. (2005). Los argonautas del pacífico occidental (1-16). Exlibris. Biblioteca del Almuense. Martínez, A. (2017). Discurso de May: "El acuerdo final sobre el Brexit se votará en el Parlamento". El Confidencial. Reino Unido. Recuperado de: https://www.elconfidencial.com/mundo/2017-01-17/theresa-may-hard-brexit-salir-mercado-unico-control-fronteras_1317431/

Monzó Nebot, E. (2003). Las socializaciones del traductor especializado: El papel de los géneros. Revista de la Facultad de Lenguas modernas, 6, p. 15-29. Recuperado de: http://www.academia.edu/308018/ Monz\%C3\%B3_Esther_2003_Las_socializaciones_del_traductor_especializado_El_papel_de_ los_g\%C3\%A9neros._Revista_de_la_Facultad_de_Lenguas_Modernas_6_15-29 
San José Beltrán, L. (2014). Vikingos. Una guía histórica de la serie de History Channel. Barcelona: Quarentena.

San José Beltrán, L. (2015). Análisis histórico de la serie Vikingos de History Channel. En: Los Vikingos en la Historia, 2 (pp.25-72). HUM-165: Patrimonio, Cultura y Ciencias Medievales. Granada: Universidad de Granada. Recuperado de: https://www.academia.edu/19601491/ An\%C3\%A1lisis_hist\%C3\%B3rico_de_la_serie_Vikingos_de_History_Channel

Todorov, T. (2008). El miedo a los bárbaros. Barcelona: Galaxia Gutemberg.

Tous, A. (2010). La era del drama en televisión. Perdidos, C.S.I.: Las Vegas, El ala Oeste de la Casa Blanca, Mujeres Desesperadas y House. Barcelona: UOC. 